\title{
Characteristics of Chlorine Emission during Rice Husk Combustion
}

\author{
Rong CHEN ${ }^{1, a}$, Yan-Yu GAO ${ }^{1, b}$, Tian-Shun ZHANG ${ }^{1, c}$, Jia-Xin ZHENG ${ }^{1, d^{*}}$, \\ Yu Al ${ }^{1, e}$, Yue RAO ${ }^{1, \mathrm{f}}$ and Shao-Jie ZHANG ${ }^{1, g}$ \\ ${ }^{1}$ College of Electrical and Mechanical Engineering, Yunnan Agricultural University, Kunming, \\ Yunnan 650201, China \\ Author profile: Chen Rong(1986-), female, born in Mile city, Yunnan, lecturer, \\ Dr.;devoted to new energy use technology; \\ a E-mail:15808841895@163.com; b E-mail:92851487@qq.com; ' ${ }^{\mathrm{C}}$-mail :351997207@qq.com; \\ dE-mail:zhengjiaxin_0628@126.com
}

Corresponding author: Zheng Jiaxin(1988-), female, born in Jilin city, Jilin

Province, Dr.;devoted to conservation tillage technology and intelligent agriculture equipment;

Found: Yunnan Younth Fund (2017FD080)

Keywords: Chlorine in rice husk; micron fuel; combustion atmosphere; reaction kinetic

\begin{abstract}
The erosion of heating surfaces due to chloride release from direct rice husk combustion was investigated. Relationships between chloride release from rice-husk combustion and different influence factors were studied and chloride release models were established. A gas-state chloride absorption testing platform was built according to the characteristics of chloride production from rice husk combustion in real boilers. The chloride release under different designing parameters was absorbed by a $\mathrm{NaOH}$ solution, and the chloride release laws during rice husk combustion were investigated. It was found the chloride release was accelerated in a multistage way with the rise of combustion temperature. The chloride release rate increased up to $85 \%$ with the prolonging of combustion time. Under the strong oxidative atmosphere, the chloride release rate increased significantly and rose by about 2 times compared with the weak oxidative atmosphere. Increasing the vapor concentration would promote the chloride release from rice husk combustion. A larger size of rice husk further hindered chloride release and decomposition, and took longer time to release the same amount of chloride. Chloride release from rice husk was harder than from wood dust, and chloride release and combustion were synchronous. Chloride release during rice husk combustion was a zero-order reaction.
\end{abstract}

\section{Introduction}

Along with the rapid development of the biomass combustion technology, the harmful gas emissions from biomass combustion have become a research focus [1-3]. Compared with coals, biomass is rich in chlorine and alkaline substances, and during the combustion, easily volatilizes into slagging and ash flouling of the heat exchanger of boiler systems, causing abrasion and erosion to the heating surfaces of heat exchangers [4-5]. Regarding such abrasion and erosion, researchers from Denmark and the US started to study these problems very early and provided much data, but Chinese researchers began very late [6].

The ash flouling, slagging, abrasion and erosion of boilers and heat exchangers during biomass combustion are critically attributed to chlorine [7]. Chlorine plays a transporting role in biomass combustion, favors the volatilization of alkali metals from biomass fuel particles, and chemically reacts with other substances on the surfaces of fuel particles. Compared with volatile alkali metals, the volatile chlorides are very stable and tend to deposit at the downstream of the equipment. Moreover, chlorine also increases the fluidity of inorganic compounds, especially potassium compounds [8-9]. It is indicated chlorine decides the total yield of alkali metal vapor.

The chlorine release should be critically characterized in order to prevent ash flouling, slagging, abrasion and erosion during biomass combustion [10]. In this study targeting at rice husk, the 
cnıoride release rules during rice-husk combustion were tested, so as to determine the relationships between chloride release and different influence factors and to construct chloride release models.

\section{Instruments and Methods}

\section{Materials}

Rice husk and rawdust were used as the targets which contained medium levels of chlorine. The rice husk and rawdust were collected locally in Kunming, Yunnan. The materials were crushed into particles in sizes of 90 or $250 \mu \mathrm{m}$, and then dried at $105{ }^{\circ} \mathrm{C}$ for $24 \mathrm{~h}$ and cooled for $8 \mathrm{~h}$. The industrial analysis and elemental analysis are listed in Tables 1, respectively.

Table 1 Industrial analysis and Elemental analysis of rice husk and sawdust

\begin{tabular}{|c|c|c|c|c|c|c|c|c|c|c|}
\hline \multirow{2}{*}{ Sample } & \multicolumn{5}{|c|}{ Industrial } & \multicolumn{4}{|c|}{ Elemental analysis /\% } & \multirow{2}{*}{$\mathrm{Cl} \mathrm{mg} / \mathrm{g}$} \\
\hline & $\mathrm{M}_{\mathrm{ad}}$ & $\mathrm{V}_{\mathrm{ad}}$ & $\mathrm{A}_{\mathrm{ad}}$ & $\mathrm{FC}_{\mathrm{ad}}$ & $\mathrm{C}$ & $\mathrm{H}$ & $\mathrm{O}$ & $\mathrm{N}$ & S & \\
\hline Husk & 11.6 & 75.75 & 9.19 & 15.06 & 39.82 & 5.36 & 33.54 & 1.36 & 0.2 & 0.9 \\
\hline sawdust & 7.2 & 76.04 & 6.01 & 17.95 & 45.23 & 5.25 & 36.51 & 0.12 & 0.11 & 0.6 \\
\hline
\end{tabular}

Instruments and Methods

In real boilers, the chloride formation during rice-husk particle combustion was limited by time, material and labor waste, and low measuring accuracy, which largely complicate relevant research and real measurement [11] In this study, a gas-state chloride direct absorption analytical method was used, and the experimental setup was showed in Fig. 1. The experimental system consisted of a combustion device, a gas distributing device and an absorption device. The combustion device was a tubular resistance furnace with power at $4 \mathrm{Kw}$ (Hangzhou Lantian Chemical Instruments Co. Ltd.) operated at $0-1000{ }^{\circ} \mathrm{C}$ with a temperature resolution of $1{ }^{\circ} \mathrm{C}$ and temperature control precision $<5$ ${ }^{\circ} \mathrm{C}$, and the workroom sizes were $\varphi 40 \times 600 \mathrm{~mm}^{2}$. The transparent quartz combustion tubes were sized $\varphi 34 \times 1000 \mathrm{~mm}^{2}$, and could tolerate up to $1300{ }^{\circ} \mathrm{C}$. The fuels were put into a small porcelain boat $\left(60 \times 30 \times 15 \mathrm{~mm}^{3}\right)$. The gas was supplied by a compressed air steel cylinder, and the gas flow rate was controlled by a decompression valve and a mass flow meter.

Samples $(250 \mu \mathrm{m}, 0.2 \mathrm{~g})$ were put into the porcelain boat, and sent by a putter into the hightemperature zone of the resistance stove. Under standard working conditions, the oxygen flow was $500 \mathrm{ml} / \mathrm{min}$, and the generated gas was absorbed by two absorption bottles in series filled with 50 $\mathrm{ml}$ of $0.1 \mathrm{~mol} / \mathrm{L} \mathrm{NaOH}$. The $\mathrm{HCl}$ gas was collected every $20 \mathrm{~min}$. After the collection, the absorption liquid was diluted to $100 \mathrm{ml}$, and the chlorine concentrations were detected via an Asca potassium thiocyanate method. It was found this absorption method fully met the experimental requirements and could absorb up to $94 \%$ of gas chloride [11].

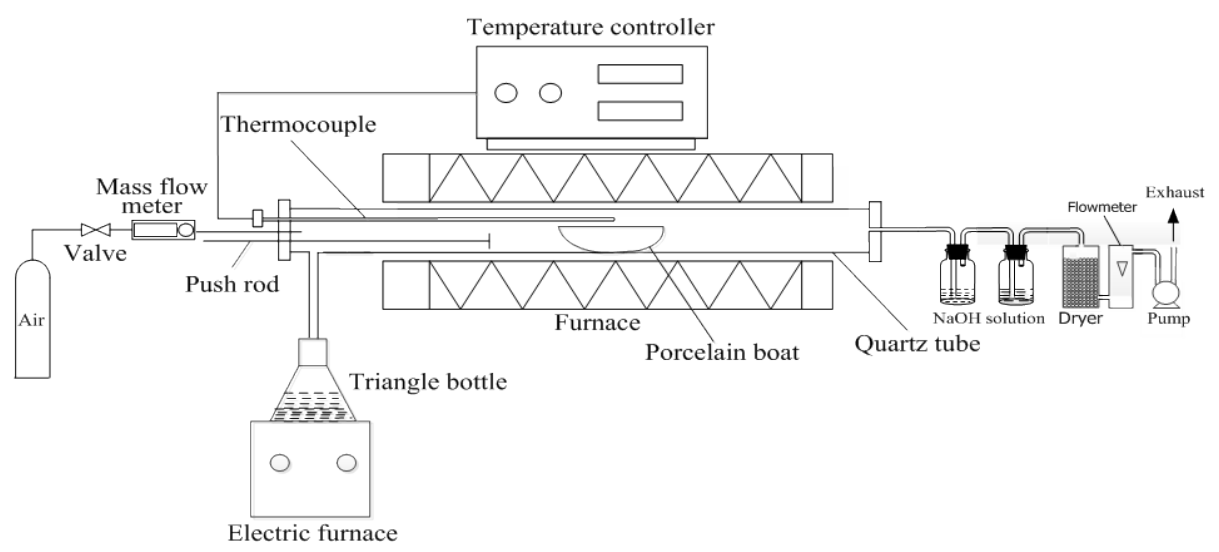

Fig. 1 The absorption experiment system of gas phase chloride 


\section{Results and Analysis}

\section{Effects of Combustion Atmosphere on Chloride Release}

The rice-husk combustion would experience the alternation between reductive and oxidative atmosphere [14], which would affect the chlorine release. To analyze such effect, we set the experimental conditions at rice-husk specimen dosage $=0.2 \mathrm{~g}$, temperature at $900{ }^{\circ} \mathrm{C}$, retention time $=30 \mathrm{~min}$, and oxygen ventilation amount $=50-800 \mathrm{ml} / \mathrm{min}$ (Fig. 2).

Clearly, as the oxygen ventilated amount increased, the chloride release rate first rose and then decreased, and stabilized around $75 \%$ within $400-500 \mathrm{ml} / \mathrm{min}$ (Fig. 2). As the $\mathrm{O}_{2}$ ventilated amount decreased at the range below $400 \mathrm{ml} / \mathrm{min}$ (namely the oxidative atmosphere in the furnace was weakened), the chloride release rate decreased significantly from $75 \%$ to about $22 \%$. When the $\mathrm{O}_{2}$ ventilated amount was over $500 \mathrm{ml} / \mathrm{min}$, the intratubular gas flow rate rose and led to the entrance of abundant cold gas, thereby reducing the combustion temperature and thereby the chlorine release. These results suggest the optimal $\mathrm{O}_{2}$ ventilated amount was $400-500 \mathrm{ml} / \mathrm{min}$.

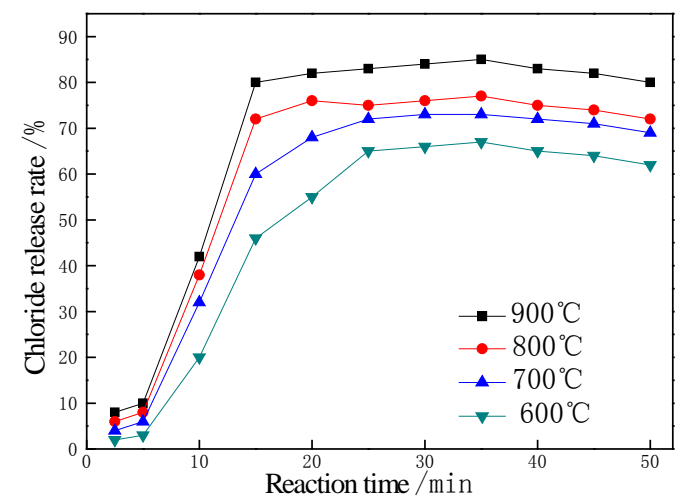

Fig. 2 Effects of oxygen on chlorine release

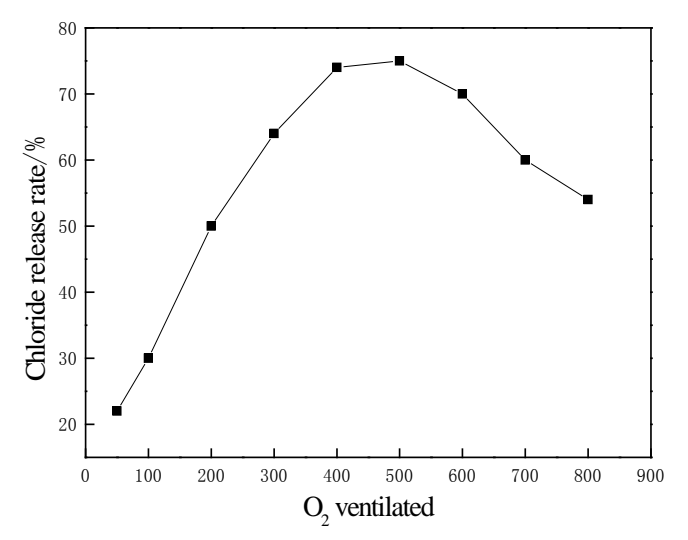

Fig. 3 Effects of burning time on chlorine release

\section{Effects of Burning Time on Chloride Release}

The chloride release during rice-husk combustion was also related to the residence time of rice-husk in the furnace, in addition to combustion temperature and combustion atmosphere. The effects of combustion temperature from 600 to $900{ }^{\circ} \mathrm{C}$ were tested at rice-husk specimen dosage of $0.2 \mathrm{~g}$ and $\mathrm{O}_{2}$ ventilated amount $=500 \mathrm{ml} / \mathrm{min}$ (Fig. 3).

At the combustion temperature $900{ }^{\circ} \mathrm{C}$, the chloride release rate was the largest (about $80 \%$ ) from 0 to $15 \mathrm{~min}$, in which the released chlorine was mostly active organic chlorine. After $15 \mathrm{~min}$, the chloride release rate was significantly slowed down to about $85 \%$, from which it was thought the $\mathrm{HCl}$ release from the rice-husk was basically stable and chloride was released in the form of ions. Beyond the reaction time of $35 \mathrm{~min}$, the chloride release rate decreased, which was mainly because too long residence time increased the amount of the absorption liquid and affected the accuracy of chlorine concentration measurement.

\section{Effects of Vapor on Chloride Release}

During the high-temperature combustion of rice-husk, evaporation also significantly affected rice-husk combustion. The effects of evaporation were tested at combustion temperature $=900$ or $700{ }^{\circ} \mathrm{C}$, rice-husk dosage of $0.2 \mathrm{~g}$ and $\mathrm{O}_{2}$ ventilated amount $=500 \mathrm{ml} / \mathrm{min}$ (Fig. 4). 


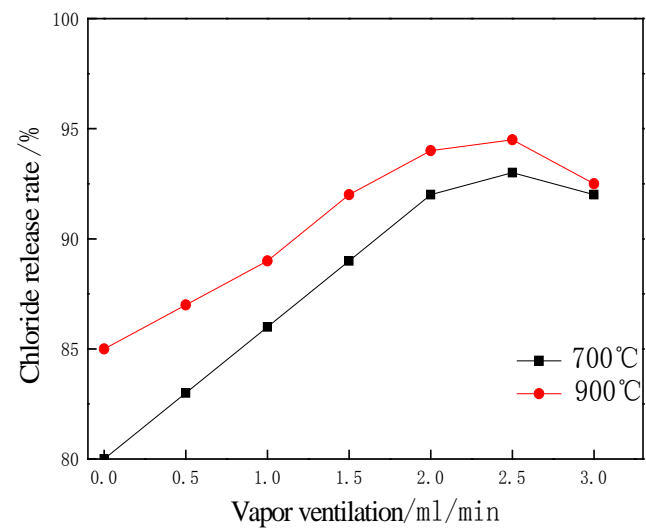

Fig. 4 Effects of water vapor on chlorine release

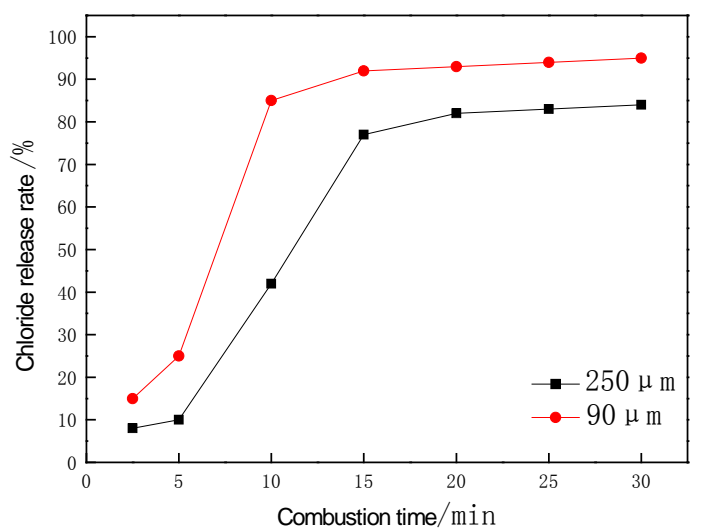

Fig. 5 Effects of particle size on chlorine release

At $700{ }^{\circ} \mathrm{C}$, the chloride release rate without vapor ventilation was about $80 \%$, and then it significantly rose with the increasing vapor ventilation. The chloride release rate rose linearly as the vapor ventilation increased from 0 to $2 \mathrm{ml} / \mathrm{min}$, but rose slowly when the vapor ventilation exceeded $2 \mathrm{ml} / \mathrm{min}$, when the promoting effect of vapor on chloride release was weakened. At higher combustion temperature of $900{ }^{\circ} \mathrm{C}$, with the rise of vapor ventilation, the increasing rate of chloride release was slowed down, and the chloride release rate without vapor ventilation (84.9\%) was larger than that at $700{ }^{\circ} \mathrm{C}$. The above results suggest vapor promotes the chloride release and significantly accelerates the chloride release from rice-husk. The chloride hydrolysis reactions showed since the participation of vapor in the combustion led to abundant chloride release, and the chloride release rate was faster at middle and low temperatures, and the appropriate vapor ventilation was $2 \mathrm{ml} / \mathrm{min}$.

\section{Effects of Particle Size on Chloride Release}

As reported, with the decrease of particle size, the chlorine content in coals declines, which is mainly because the moisture evaporation during sample grinding brought away a part of chlorine [15]. Rice- husk particle size affects the chlorine contents in a similar way. This is because rice-husk crushing was accompanied with mechanical chemistry actions and thereby exothermic reaction, which led to partial moisture evaporation from the rice-husk, and induced the temperature rise in the small-size rice-husk particles, leading to the reduction of chlorine concentrations in the small-size rice-husk particles.

The effects of particle size $(90,250 \mu \mathrm{m})$ were tested at combustion temperature $900{ }^{\circ} \mathrm{C}$, oxygen ventilated amount of $500 \mathrm{ml} / \mathrm{min}$ and specimen dosage of $0.2 \mathrm{~g}$. The temporal changes of chloride release with particle size are showed in Fig. 5.

Clearly, with the rise of particle size, the chloride release was gradually slowed down, and its curve moved backwards with the prolonging of burning time, indicating larger particle size was less favorable for chlorine release. At the initial residence in the furnace (2.5-5 s), the smaller-size chloride was released faster. After residence in the furnace for more than $15 \mathrm{~s}$, the chloride release rates of the two particle sizes both basically stabilized, and the effect of particle size on the chloride release at later stages was gentle. On this basis, the effect of particle size on chlorine release was dominated by chemical thermodynamics and kinetics.

\section{Chloride Release of Different Biomasses}

Rice-husk with $0.09 \%$ chlorine and sawdust with $0.06 \%$ chlorine were tested. The tests with specimens (each $0.2 \mathrm{~g}$ ), oxygen ventilated amount of $500 \mathrm{ml} / \mathrm{min}$, residence time of $20 \mathrm{~min}$, and temperature from 200 to $970{ }^{\circ} \mathrm{C}$ were conducted. During the rice-husk combustion, chlorine was mainly released in the form of $\mathrm{HCl}$. Clearly, the $\mathrm{HCl}$ release rate significantly rose with the rise of combustion temperature. During the rice-husk combustion, $\mathrm{HCl}$ release started at $200{ }^{\circ} \mathrm{C}$, exceeded $80 \%$ at $600{ }^{\circ} \mathrm{C}$ and rose to about $96 \%$ at $970{ }^{\circ} \mathrm{C}$, indicating the majority of chlorine was released from the rice-husk at $600{ }^{\circ} \mathrm{C}$. On this basis, the chloride release process was divided into three stages: $200-300,300-600$, and $>600{ }^{\circ} \mathrm{C}$. About $50 \%$ of chloride was released from the rice-husk at the second stage; organic chlorine was released below $600{ }^{\circ} \mathrm{C}$, and inorganic chlorine was released 
at above $600{ }^{\circ} \mathrm{C}[15]$.

The chloride release rates from rice-husk and sawdust both increased in a multi-stage way with the rise of combustion temperature, and the uptrends were very similar. The chloride release rates were very low within $200-300{ }^{\circ} \mathrm{C}$, and the majority of chlorine was released at $300-600{ }^{\circ} \mathrm{C}$, in which the chloride release rate significantly increased with the rise of combustion temperature and exceeded $80 \%$. The chloride release rate increased slowly and basically became consistent beyond $600{ }^{\circ} \mathrm{C}$.

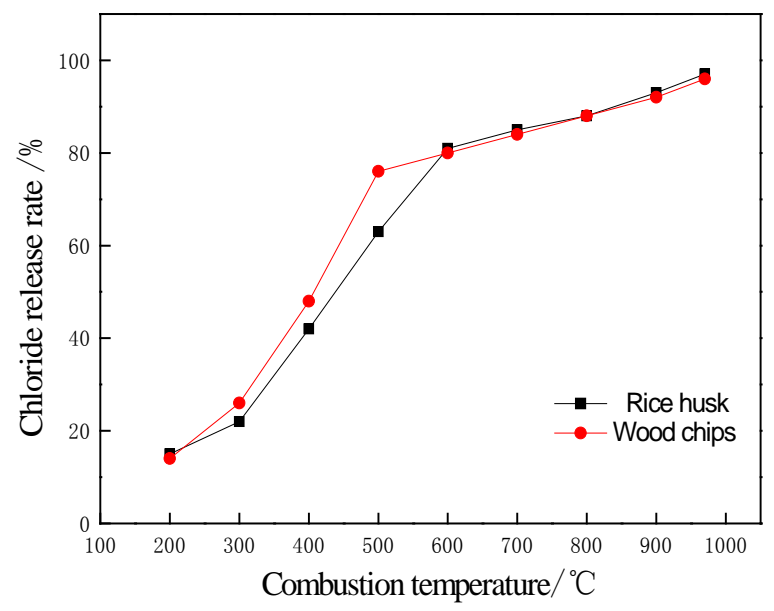

Fig. 6 Effects of biomass on chlorine release

The above analyses indicate at $200-300{ }^{\circ} \mathrm{C}$, mainly volatiles were released from either rice-husk or sawdust, but the released amount was very small, about $10 \%$ of chloride release from rice-husk or sawdust. These results suggest the less chlorine was released with the volatiles, and mainly occurred at the carbon combustion stage. As reported, the chloride release rate within $300-600{ }^{\circ} \mathrm{C}$ was significantly higher than at other temperatures, and the majority of chloride released was inorganic chlorine [16-17]. At below $300{ }^{\circ} \mathrm{C}$, organic or water-soluble chlorine in the form of Cl-Cl, and a small amount of inorganic chloride were released, and the majority of inorganic chlorine was stable. At above $600{ }^{\circ} \mathrm{C}$, the chlorine release was very slow and seemed extremely difficult. As reported, the residual chlorine at below $600{ }^{\circ} \mathrm{C}$ was more stable than the released chlorine, and would be only released at higher temperature [18].

\section{Chloride Release Model from Rice-Husk Combustion}

Garcia-Labiano[19] thought when the differences in the chlorine hosted forms of biomass and the intermediates from chloride release reactions were ignored, the solid-phase chlorine in biomass could be directly converted to $\mathrm{HCl}$ :

$$
\mathrm{Cl}(\text { solid })+\mathrm{H}^{+} \rightarrow \mathrm{HCl} \text {. }
$$

If the reactions at different temperatures were all isothermal, volume-constant irreversible zero-order reactions, then the $\mathrm{HCl}$ formation rate and its integral form were [20]:

$$
\begin{aligned}
& -\frac{d M}{d \tau}=k . \\
& k \tau=M_{0}-M .
\end{aligned}
$$

where $M_{0}$ and $M$ were the initial and final $\mathrm{Cl}$ concentrations o $\mathrm{HCl}$ at a certain temperature $\left(\mu \mathrm{g} \cdot \mathrm{g}^{-1}\right) ; k$ was the reaction rate constant; $\tau$ was the reaction time.

The reaction rate constant $k$ obeys the Arrhenius equation:

$$
k=A e^{-E / R T} .
$$

where $A$ was a frequency factor, $\min ^{-1} ; E$ was the activation energy, $\mathrm{kJ} / \mathrm{mol}$; $\mathrm{R}$ was a gas constant, $\mathrm{kJ} / \mathrm{mol} \cdot \mathrm{K}$; $\mathrm{T}$ was reaction temperature, $\mathrm{K}$. As showed in Fig. 3, the reaction rates $\mathrm{k}$ at different combustion temperatures could be calculated (Table 2). 
Iable 2 The reaction rate of $\mathrm{HCl}$ the rice husk combustion under different combustion temperatures

\begin{tabular}{cc}
\hline Temperature $\mathrm{t} /{ }^{\circ} \mathrm{C}$ & Reaction rate $\mathrm{k} / \mathrm{mg} \cdot \mathrm{s}^{-1}$ \\
\hline 600 & 0.00648 \\
700 & 0.00952 \\
800 & 0.01188 \\
900 & 0.01296 \\
\hline
\end{tabular}

The two sides were logarithm-treated, then:

$$
\ln k=\ln A-\frac{E}{R} \cdot \frac{1}{T} .
$$

The frequency factor A and activation energy E were computed (Table 3). Arrhenius equation can be written as:

$$
k=1.2913 e^{-\frac{11.37}{R T}}
$$

Table 3 The kinetic parameters of chloride precipitation by rice husk

\begin{tabular}{cccc}
\hline & Frequency & & \\
Sample & factor & Reaction kinetics & Correlatio \\
& $\mathrm{A} / \mathrm{min}$ & $\mathrm{kJ} \cdot \mathrm{min}^{-1}$ & $\mathrm{n}$ \\
& & & coefficient \\
\hline $\begin{array}{c}\text { Rice } \\
\text { husk }\end{array}$ & 1.2913 & 11.3719 & 0.9869 \\
\hline
\end{tabular}

\section{Conclusions}

In the self-made fixed-tube resistance furnace, the chloride release from biomass combustion was characterized via the gas-phase chloride absorption method.

(1) The chlorine release from rice-husk combustion was mainly in the form of gas-phase chlorine $(\mathrm{HCl})$, and was affected by combustion temperature, residence time, combustion atmosphere, and particle size.

(2) The chloride release rate was accelerated in a multistage way with the rise of combustion temperature. The chloride release rate increased up to $85 \%$ with the prolonging of combustion time. Under the strong oxidative atmosphere, the chloride release rate increased significantly and rose by about 2 times compared with the weak oxidative atmosphere. Increasing the vapor concentration would promote the chloride release from rice husk combustion. A larger size of rice husk further hindered chloride release and decomposition, and consumed longer time for the same amount of chloride release. Chloride release from rice husk was harder than from wood dust, and chloride release and combustion were synchronous.

(3) During rice-husk combustion, the chloride release was a zero-order reaction: $k=1.2913 e^{-\frac{11.37}{R T}}$.

\section{References}

[1] Yan Jinding. The current development situation and the strategic thinking of the biomass energy in China. Forest Chemistry and Industry, 2014,34(4):151-158. 
[2]M. Kratzeisen, J. Müller. Suitability of Jatropha seed shells as fuel for small-scale combustion units. Renewable Energy, 2012, 51(2013):46-52

[3] Feng Duan, Chien-Song Chyang, Chien-Wei Lin, Jim Tso. Experimental study on rice husk combustion in a vortexing fluidized-bed with flue gas recirculation. Bioresource Technology,2013,134(2013): 204-211

[4] Feng Duan, Chiensong Chyang, Yucheng Chin, Jim Tso. Pollutant emission characteristics of rice husk combustion in a vortexing fluidized bed incinerator. Journal of environmental sciences, 2013, 25(2):335-339

[5]Chi Zuohe et al.. Then research of the slagging mechanism and the prevent slagging technology in boiler[J]. Thermal Power Generation, 1999(4).

[6] Yang Wen, Ji Xiaoyu, Dong Kai, Song Xingfei, Bie Rushan. Releasing characteristics of chlorine and alkali metals( $\mathrm{K}$ and $\mathrm{Na}$ ) in process of biomass combustion[J]. Journal of Solar Energy, 2015,36(12):3072-3075.

[7]Amand L E, Kassman H.Decereased PCDD/F formation when co-firing a waste fuel and biomass in a CFB boiler by addition of sulphates or municipal sewage sludage[J].Waste management,2013,33(8):1729-1739

[8]Han Xu, Zhang Yanfeng, Yao Dingding, et al. The separation characteristic research of alkali metal and alkaline earth metal in the process of biomass gasification[J]. Journal of Chemical Fuel, 2014,42(7):792-798

[9]Zhang Zhihao. The research of alkali metal element migration in process of biomass thermal conversion[D]. Tsinghua University, 2014.

[10] Peter Thy, Jenkins B M, Lesher C E, et al. Compositional constraints on slag formation and potassium volatilization from rice straw blended wood fuel [J].Fuel Processing Technology, 2006,87(5):383-408.

[11]Jiang Xuguang, Xu xu, Yan Jianhua, He Jie, Chi Yong, Cen Kefa. The research of chloride precipitation characteristics in the process of coal combustion[J] . Journal of Coal,2012,27(4) : 398-401

[12] Liang Juanjuan, Li Xiaodong, Yan Mi, Lu Shenyong, Yan Jianhua. Inorganic chlorine released from typical components of medical waste in pyrolysis/incineration[J]. Chemical Industry and Engineering Progress, 2012,31(4): 927-932

[13] Jiang Lei, Wang Yongjun, Yu Tao, et al. The analysis of corrosion mechanism about the sulfur and chlorine in the process of biomass and coal combustion[J]. Power System Engineering,2013,29(3):1-4.

[14] Xia Wu, Li-ping Xie, Xin-yu Li, Xiao-hong Dai, Xue-ning Fei,Yuan-guang Jiang. Effect of wastewater treatment processes on the pyrolysis properties of the pyrolysis tars from sewage sludges. Journal of Thermal Science,2011,20(2):167-172

[15] Barmina I , Desnickis A, Zake M. The influence of the electric field on the development of the swirling flame velocity field and combustion characteristics. HEAT TRANSFER RESEARCH, 2008, 39(5):371-378

[16]Johansen J M, Jakobsen J G, Frandsen F J, et al.Release of K,Cl,and S during combustion and co-combustion with wom od of high-chlorine biomass in bench and pilot scale fuel beds[J]. Proceedings of the Combustion Institute,2013,34(2):2363-2372.

[17] Wang Yong-zheng, Jiang Lei, Yue Mao-zhen, et al. Study on detection methods for chlorine precipitation during biomass and coal co-combustion[J].Advanced Mechanics and Materials,2012,229-231:1423-1426. 
[18] Matsuda H, Ozawa S, Naruse K, Ito K, Kojima Y, Yanase T. Kinetics of HCl emission from inorganic chlorides in simulated municipal wastes incineration conditions [J]. Chem Eng Sci. 2005, 60:545-552.

[19]Du Shenglei, Yang Haiping, Qian Kezhen, et al. The research of migration law about alkali and alkaline earth metal in the process of biomass pyrolytic [J]. Proceedings of the CSEE, 2013(26):48-53.

[20]Martin Bejera, Peter Arendt Jensena, Flemming Frandsena, et al. Alkali/Chloride release during refuse incineration on a grate: Full-scale experimental findings [J].Fuel processing Technology,2008,89(5):528-53. 